\title{
Challenges in early cardiothoracic surgery: Aortic homograft transplantation in coarctation, a 44-year follow-up
}

\author{
R. von Wattenwyl, MD, M. T. R. Grapow, MD, D. C. Reineke, MD, and H.-R. Zerkowski, MD, Basel, Switzerland
}

$\mathrm{W}$

e present the case of a woman now 72 years old whom we were surprised to find up and healthy in our outpatient clinic.

\section{Clinical Summary}

In 2001, a 68-year-old patient came in for a routine checkup in our outpatient clinic. In 1957, she had undergone an operative correction of a coarctation of the aorta. This operation was performed by Rudolph Nissen (1896-1981), who was at the time professor of surgery at the University of Basel. While still in school, the patient had hypertension and cardiomegaly diagnosed during routine physical examinations. Years later, excessive hypertension with systolic pressures as great as $200 \mathrm{~mm} \mathrm{Hg}$ forced the family practitioner to initiate medical treatment. Further investigation revealed coarctation of the aorta (Figure 1). Surgical correction seemed the only therapeutic option to avoid further damage to the heart.

\section{Operative Technique and Findings}

Because of severe calcification and anatomic particulars, the intervention proved to be extremely difficult. Classic repair formssuch as bridging the defect with subclavian artery, plastic methods in which the left subclavian artery is of inadequate diameter (as described by Johnson and colleagues ${ }^{1}$ ), resection of the coarcted part and end-to-end anastomosis-were impossible. Confronted with these unexpected circumstances, Nissen had to abort the operation. Nissen considered the interposition of an allograft. At that time, officially coordinated organ donor databases and artificial grafts were both nonexistent. These special circumstances made it necessary to seek actively for a donor. In the meantime, the patient was treated conservatively.

From the Division of Cardio-Thoracic Surgery, University Hospital, Basel, Switzerland.

Received for publication March 16, 2006; accepted for publication April 10, 2006.

Address for reprints: R. von Wattenwyl, MD, Division of Cardio-Thoracic Surgery, University Hospital Basel, Spitalstrasse 21, CH-4031 Basel, Switzerland (E-mail: vonwattenwylr@uhbs.ch).

J Thorac Cardiovasc Surg 2006;132:969-70

$0022-5223 / \$ 32.00$

Copyright (๑) 2006 by The American Association for Thoracic Surgery doi:10.1016/j.jtcvs.2006.04.050

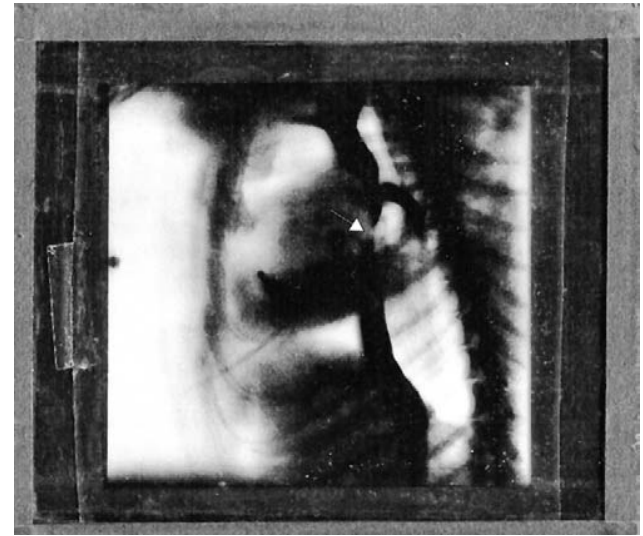

Figure 1. Original glass slide with aortic coarctation (arrow).

After a donor aorta was found 2 months later, it was finally possible to replace the coarctated part of the aorta (Figure 2, A, p. 970). There were no intraoperative or perioperative complications, and the patient was discharged after 5 weeks.

\section{Follow-up}

The patient in question was able to resume a normal life and later gave birth to a healthy son. Hypertension clearly improved, and with antihypertensive treatment an almost normal blood pressure was achieved. In 1994, the patient once again had to be hospitalized, for sepsis of unknown origin that was successfully treated with antibiotics. A computed tomographic scan of the aorta only showed heavily calcification, without any evidence for an infectious process (Figure 2, B). Routine check-ups since have been uneventful. ${ }^{2-5}$

\section{References}

1. Johnson J, Kirby C, Hardy JD. Aneurysm formation in experimental vein grafts in the thoracic aorta. Surgery. 1957;33:207-12.

2. Howard J. Historical vignettes of arterial repair: recollections of Korea 1951-1953. Ann Surg. 1998:228:716-8.

3. Bailey CP. Coarctation of the aorta. In: Bailey CP, editor. Surgery of the heart. London: Henry Kimpton; 1955. p. 134-79.

4. Svensson LG, Crawford ES. Congenital abnormalities of the aorta in adults. In: Svensson LG, Crawford ES, editors. Cardiovascular and vascular disease of the aorta. Philadelphia: WB Saunders; 1997. p. 153-74.

5. Rodriguez JA. Coarctation of the aorta. In: Rodriguez JA, editor. An atlas of cardiac surgery. Philadelphia: WB Saunders; 1957. p. 73-83. 

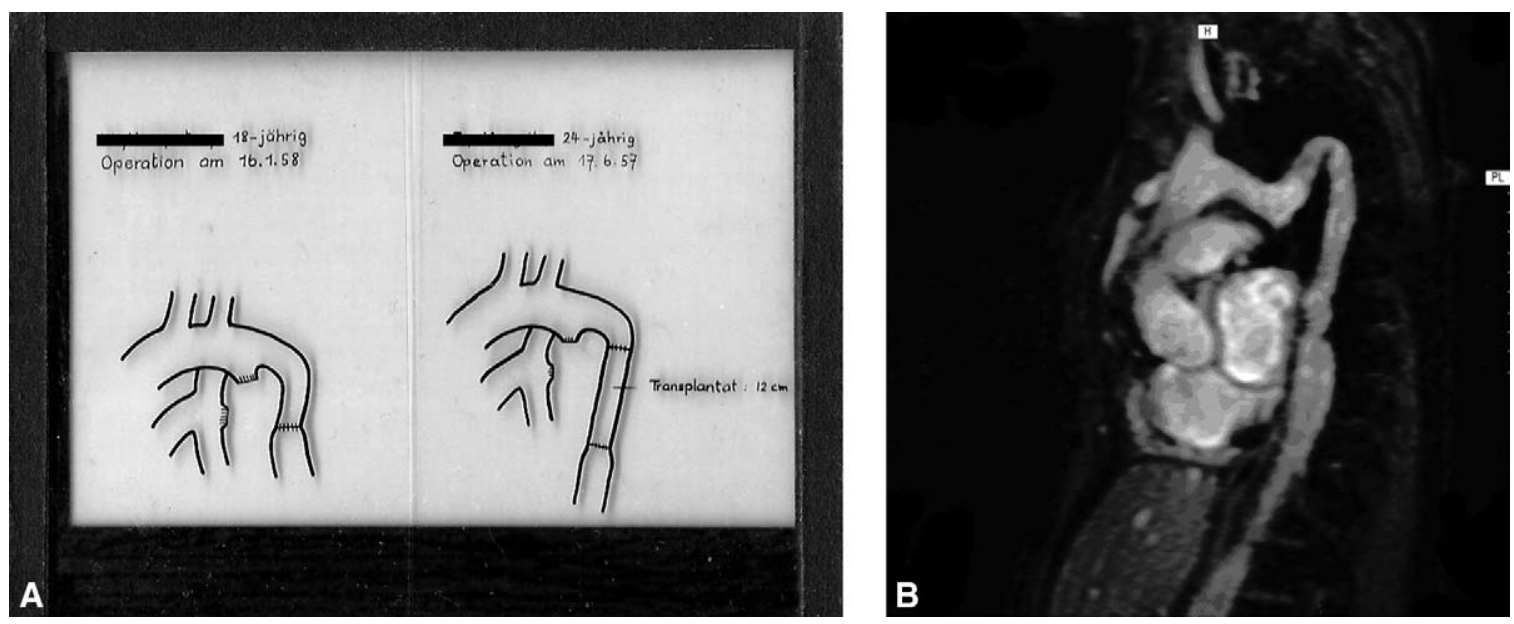

Figure 2. A, Original slide with Nissen's drawings showing technical procedure in general (right side of slide demonstrates situation in our patient). B, Computed tomographic scan, performed in 1992, shows calcification of replaced part of aorta. See also p. 969.

\section{Repair of anomalous right and circumflex coronary arteries arising from the pulmonary artery}

Giovanni Battista Luciani, MD, ${ }^{a}$ Fauzia Vendrametto, MD, ${ }^{\mathrm{b}}$ Luca Barozzi, MD, ${ }^{a}$ Rainer Oberhollenzer, MD, ${ }^{\mathrm{b}}$ Walter Pitscheider, MD, ${ }^{b}$ and Alessandro Mazzucco, MD, ${ }^{a}$ Verona and Bolzano, Italy

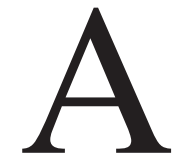

nomalous origin of the right coronary artery (RCA) from the pulmonary artery (PA; ARCAPA) is a rare congenital anomaly. In the last 40 years, 72 cases have been described, and 40 patients have undergone repair. ${ }^{1-3}$ Origin of the circumflex coronary artery $(\mathrm{CxA})$ from the PA (ACCAPA) is even more unusual, with only 12 patients identified in the literature. ${ }^{4,5}$ Contrary to ARCAPA, anomalous origin of the $\mathrm{CxA}$ is frequently associated with other cardiac anomalies, although isolated ACCAPA has been reported. ${ }^{4,5}$ Different from the low mortality $(5 \%)$ associated with repair of the former anomaly, ${ }^{1-3}$ the risk of operation for ACCAPA appears

\footnotetext{
From the Division of Cardiac Surgery, University of Verona, ${ }^{\text {a }}$ Verona, Italy, and the Division of Cardiology, Bolzano City Hospital, ${ }^{\mathrm{b}}$ Bolzano, Italy.

Received for publication March 21, 2006; revisions received May 5, 2006; accepted for publication May 12, 2006.

Address for reprints: Giovanni Battista Luciani, MD, Division of Cardiac Surgery, University of Verona, O. C. M. Piazzale Stefani 1, Verona 37126, Italy (E-mail: gbluciani@yahoo.com).

J Thorac Cardiovasc Surg 2006;132:970-2

$0022-5223 / \$ 32.00$

Copyright @ 2006 by The American Association for Thoracic Surgery doi:10.1016/j.jtcvs.2006.05.053
}

high (29\%). ${ }^{4}$ Here we describe a previously unreported congenital anomaly consisting of origin of both the RCA and CxA from the main PA successfully repaired by means of coronary reimplantation.

\section{Clinical Summary}

A 51-year-old man with an unremarkable clinical history had an incidental electrocardiographic (EKG) finding of inferior wall myocardial infarction. Treadmill exercise testing confirmed inferolateral ischemia, which was reversible on exercise Thallium-201 scintigraphic scanning. Preoperative echocardiographic examination showed normal left ventricular dimensions (enddiastolic diameter, $58 \mathrm{~mm}$; end-systolic diameter, 38), preserved function (ejection fraction, $58 \%$ ), and mild mitral regurgitation. Coronary angiography demonstrated a dilated and tortuous left anterior descending artery (Figure 1) freely connected with a dilated and tortuous RCA through the posterior descending artery, septal branches, and a mesh of thin epicardial vessels (Figure 1, A). The RCA drained into the pulmonary trunk. The CxA seemed to originate from the pulmonary trunk through the RCA (Figure 1,B). Considering the young age of the patient and the evidence of silent myocardial ischemia, repair was advised. After median sternotomy, origin of both the RCA and CxA from the right-facing pulmonary sinus through the common ostium was confirmed: the $\mathrm{CxA}$ coursed anterior to 